\title{
The Debate on Influencing Doctors' Decisions: Are Drug Characteristics the Missing Link?
}

\author{
Sriram Venkataraman and Stefan Stremersch
}

\begin{tabular}{|l|l|}
\hline \multicolumn{2}{|l|}{ ERIM REPORT SERIES RESEARCH IN MANAGEMENT } \\
\hline ERIM Report Series reference number & ERS-2007-056-MKT \\
\hline Publication & September 2007 \\
\hline Number of pages & 37 \\
\hline Persistent paper URL & \\
\hline Email address corresponding author & stremersch@few.eur.nl \\
\hline Address & Erasmus Research Institute of Management (ERIM) \\
& RSM Erasmus University / Erasmus School of Economics \\
& Erasmus Universiteit Rotterdam \\
& P.O.Box 1738 \\
& 3000 DR Rotterdam, The Netherlands \\
& Phone: + 31104081182 \\
& Fax: $\quad+31104089640$ \\
& Email: info@erim.eur.nl \\
& Internet: www.erim.eur.nl \\
\hline
\end{tabular}

Bibliographic data and classifications of all the ERIM reports are also available on the ERIM website: www.erim.eur.nl 


\section{ERASMUS RESEARCH INSTITUTE OF MANAGEMENT}

\section{REPORT SERIES \\ RESEARCH IN MANAGEMENT}

\begin{tabular}{|c|c|}
\hline \multicolumn{2}{|c|}{ ABSTRACT AND KEYWORDS } \\
\hline Abstract & $\begin{array}{l}\text { Decision-making by physicians on patients' treatment has come under increased public scrutiny. } \\
\text { In fact, there is a fair amount of debate on the effects of marketing actions of pharmaceutical } \\
\text { firms toward physicians and their impact on physician prescription behavior. While some } \\
\text { scholars find a strong and positive influence of marketing actions, some find only moderate } \\
\text { effects, and others even find negative effects. Debate is also mounting on the role of other } \\
\text { influencers (such as patient requests) in physician decision-making, both on prescriptions and } \\
\text { sample-dispensing. The authors argue that one factor that may tip the balance in this debate is } \\
\text { the role of drug characteristics, such as a drug's effectiveness and a drug's side effects. } \\
\text { Using a unique data set, they show that marketing efforts - operationalized as detailing and } \\
\text { symposium meetings of firms to physicians - and patient requests do affect physician decision- } \\
\text { making differentially across brands. Moreover they find that the responsiveness of physicians' } \\
\text { decision-making to marketing efforts and patient requests depends upon the drug's effectiveness } \\
\text { and side effects. The paper presents clear guidelines for public policy and managerial practice } \\
\text { and envisions that the study of the role of drug characteristics - such as effectiveness and side } \\
\text { effects - may lead to valuable insights in this surging public debate. }\end{array}$ \\
\hline Free Keywords & $\begin{array}{l}\text { Physician decision-making, marketing efforts, patient requests, drug effectiveness, side effects, } \\
\text { drug prescription, sampling, sample-dispensing, pharmaceuticals, public policy }\end{array}$ \\
\hline Availability & $\begin{array}{l}\text { The ERIM Report Series is distributed through the following platforms: } \\
\text { Academic Repository at Erasmus University (DEAR), DEAR ERIM Series Portal } \\
\text { Social Science Research Network (SSRN), SSRN ERIM Series Webpage } \\
\text { Research Papers in Economics (REPEC), REPEC ERIM Series Webpage }\end{array}$ \\
\hline Classifications & $\begin{array}{l}\text { The electronic versions of the papers in the ERIM report Series contain bibliographic metadata } \\
\text { by the following classification systems: } \\
\text { Library of Congress Classification, (LCC) LCC Webpage } \\
\text { Journal of Economic Literature, (JEL), JEL Webpage } \\
\text { ACM Computing Classification System CCS Webpage } \\
\text { Inspec Classification scheme (ICS), ICS Webpage }\end{array}$ \\
\hline
\end{tabular}




\title{
The Debate on Influencing Doctors' Decisions: Are Drug Characteristics the Missing Link?
}

\author{
Sriram Venkataraman \\ Assistant Professor of Marketing, 1300 Clifton Road, Goizueta Business School Emory University, Atlanta, GA 30322-2710, svenka2@emory.edu \\ Stefan Stremersch ${ }^{1}$ \\ Professor of Marketing, School of Economics, Erasmus University Rotterdam, Burg. Oudlaan 50, 3000 DR Rotterdam, The Netherlands. \\ Visiting Associate Professor of Marketing, Goizueta Business School, Emory University, Atlanta, GA 30322-2710. \\ stremersch@,few.eur.nl
}

\begin{abstract}
Decision-making by physicians on patients' treatment has come under increased public scrutiny. In fact, there is a fair amount of debate on the effects of marketing actions of pharmaceutical firms toward physicians and their impact on physician prescription behavior. While some scholars find a strong and positive influence of marketing actions, some find only moderate effects, and others even find negative effects. Debate is also mounting on the role of other influencers (such as patient requests) in physician decision-making, both on prescriptions and sample-dispensing. The authors argue that one factor that may tip the balance in this debate is the role of drug characteristics, such as a drug's effectiveness and a drug's side effects.
\end{abstract}

Using a unique data set, they show that marketing efforts - operationalized as detailing and symposium meetings of firms to physicians - and patient requests do affect physician decision-making differentially across brands. Moreover they find that the responsiveness of physicians' decision-making to marketing efforts and patient requests depends upon the drug's effectiveness and side effects. The paper presents clear guidelines for public policy and managerial practice and envisions that the study of the role of drug characteristics - such as effectiveness and side effects - may lead to valuable insights in this surging public debate.

Keywords: Physician decision-making, marketing efforts, patient requests, drug effectiveness, side effects, drug prescription, sampling, sample-dispensing, pharmaceuticals, public policy.

\footnotetext{
1 Acknowledgements We thank a large pharmaceutical firm for making the data available to us. Due to a confidentiality agreement, we cannot reveal the name of our data source as well as brands used in our study. This paper has benefited from our discussions with several colleagues. In particular we thank Pradeep Chintagunta, Sachin Gupta, Puneet Manchanda, Sridhar Narayanan, Frans Rutten and Walter Van Dyck for their insightful comments and suggestions on the paper.
} 


\section{Introduction}

Decision-making by physicians regarding the drugs they treat patients with has come under increased scrutiny. As pharmaceutical expenses in the United States and other developed countries rise sharply with aging of the population, governments and regulators turn their attention to factors that may (adversely) affect physician drug decision-making. Factors that draw particular attention are marketing actions of pharmaceutical firms targeted directly at physicians and patient requests for a specific drug. "There has been a public outcry, especially in America, over the cozy relationship between doctors and drug companies. Some practices are illegal, others are simply part of the customary trio of food, flattery and friendship." (“Survey: Devil in the Detail," The Economist, June 18, 2005). The prosecution of Merck for its marketing actions for the drug Vioxx is a very recent, heavily publicized, case in point, that regulators take notice ("Merck Withheld Vioxx Safety Information...," The Wall Street Journal, March 7, 2006).

Pharmaceutical firms spend a huge and ever-increasing budget on detailing visits (sales calls by pharmaceutical representatives) and meetings. The number of sales representatives in the pharmaceutical industry has undergone a six-fold increase in the last 20 years to approximately 100,000 today, and 77 percent of the companies are planning to further expand their sales force in 2005 (Pharmaceutical Representative, April 2004). Detailing (30.6 percent) and sampling (50.6 percent) to physicians amount to 81 percent of promotion spending by pharmaceutical firms in 2000 (Rosenthal et al. 2003). In addition, patients increasingly request a certain brand of drug from the physician. In the United States, one in three patients at some point has asked about a drug by name (Medical Marketing and Media, November 2003). It is a commonly held belief that such patient requests are often triggered by direct-to-consumer (DTC) advertising, presently at an all-time high of $\$ 4$ billion in the United States (Brandweek, May 16 2005).

The most important decision of a physician, especially if it concerns general practice physicians, is which drug to use in treatment of patients. The decisions physicians make on drug treatment can be witnessed through observing prescription behavior. They can also be observed in sampling behavior, as samples are provided together with a prescription (as a financial subsidy to the patient), or instead of a 
prescription (as a trial, e.g. when uncertainty about drug-patient interaction is high). Sample-dispensing by physicians is rarely studied. Sampling is an important physician decision as well, because sampling may lead to prescribed long-term treatment (Morelli and Koenigsberg 1992), and thus have significant consequences for pharmaceutical firms and public health.

Academic scholars and regulators have turned to assessing how both marketing actions of pharmaceutical firms and patient requests influence physician decision-making on drug treatment, both prescription and sampling behavior. At this point, most research has been conducted on how marketing efforts targeted to physicians affect physicians' prescription behavior. Patient requests as a factor influencing physician decision-making and sampling as a physician decision have received less attention so far.

But even in the relatively developed research stream on marketing efforts and prescription behavior, controversy has been raised recently. While some studies (e.g. Gönül, et al. 2001), find that detailing has a positive and significant effect on prescriptions written, other studies find either a very modest effect (Mizik and Jacobson 2004) or no effect at all (Rosenthal, et al. 2003) of detailing on brand prescriptions or sales. Recently Leeflang, Wieringa and Wittink (2004) posited that the reason for these incongruent results is that prior models may be misspecified - in that they pool the effect of marketing expenditures across brands - while brands may in fact differ in the extent to which physicians are responsive to marketing expenditures a firm makes to promote them through detailing, meetings or other promotional instruments. This is also the stance we take in the present study.

This study posits that drug characteristics - such as side effects and effectiveness - are a potential source for brand-specific differences, if any, in responsiveness of physicians' brand prescription behavior to marketing efforts by pharmaceutical firms. Our insight may contribute to resolving the controversy on how marketing efforts of pharmaceutical firms affect prescription behavior. We also examine the role of these drug characteristics in the effect of other "influencers" - such as patient requests - and other physician decisions - such as sample-dispensing. A coherent picture arises from our empirical analysis. We find that drug characteristics affect both the influence patients (in this study through patient requests) 
as well as pharmaceutical firms (in this study through their marketing efforts targeted to physicians) exert on physician decision-making, both in a physician's prescription and a physician's sample-dispensing decisions. Thus, we underscore the importance of including drug characteristics in any study of influence by firms and/or patients on any drug treatment decision a physician makes. By our knowledge, no prior study has ever done that nor has advocated to do so, based on sound scientific evidence.

For this study, we have composed a unique data set that matches three data sources. The first contains detailed information on manufacturers' detailing visits to physicians, physician attendance at manufacturers' meetings, and drug requests of patients for 2,774 physicians in the United States, as well as the number of prescriptions written and samples dispensed by each of these physicians on a monthly basis. The second and third datasets we composed ourselves. These contain data on (1) effectiveness and (2) side effects of each drug in our database.

The next section discusses the theoretical background. The third section describes our data set and the analysis methodology we use. The fourth section presents our results. The fifth section discusses our findings, their implications for public policy and management practice, and the study's limitations.

\section{Background}

This section first discusses prior research on the effects of pharmaceutical firms' marketing efforts on physician prescribing and explores their effects on sampling behavior by the physician, which until today remained unstudied. Second, we discuss the limited prior research on the effects of patient requests on physicians' prescription and sample-dispensing behavior. Third, we explore the role that drug characteristics may play on physician decisions and their interactions with firms' marketing efforts and patient requests. Fourth, we discuss any other relevant variables that may affect physicians' prescription and sample-dispensing behavior. 


\subsection{Effects of pharmaceutical firms' marketing efforts on physician prescription and sample-dispensing behavior}

One can divide the prior literature regarding the effect of pharmaceutical firms' marketing efforts on individual physicians' prescription behavior into two streams, namely one finding positive effects and one finding mixed effects, at best. We discuss each stream in turn.

Gönül et al. (2001) and Manchanda and Chintagunta (2004) find that marketing efforts by pharmaceutical companies to the physician positively affect prescriptions issued by a physician, but there are diminishing returns to detailing. Manchanda, Rossi and Chintagunta (2004) find that detailing positively affects prescription behavior, but that high-volume physicians, while being detailed more, are less responsive to detailing, as compared to low-volume physicians. Narayanan (2004) finds that while detailing influenced physicians positively in an overwhelming number of cases, there was significant cross-sectional and temporal heterogeneity in physician responsiveness to detailing. Janakiraman et al. (2005) find that non-persistent physicians are responsive to both detailing and symposium meetings, while persistent physicians are only responsive to symposium meetings. Also many studies that use aggregate (sales or prescription) data find a positive effect of detailing on drug sales (e.g. Chintagunta and Desiraju 2005; Narayanan, Desiraju and Chintagunta 2004; Narayanan, Manchanda, and Chintagunta 2005; Neslin 2001; Rizzo 1999).

According to the prior literature, firms' marketing efforts may have a positive effect on prescription behavior, because detailing visits or symposium meetings provide information to the physician on efficacy and side effects of the drug (Gönül, et al. 2001). In line with a long tradition in economics (e.g. Becker and Murphy 1993; Grossman and Shapiro 1984; Leffler 1981), Narayanan, Manchanda and Chintagunta (2005) have argued that firms' marketing efforts may actually have both an informative role (e.g. reducing cognitive uncertainty) and a persuasive role (e.g. inducing positive affect).

Mizik and Jacobson (2004) find that marketing efforts by pharmaceutical companies to the physician positively affect new prescriptions issued by a physician, but the effect sizes are very modest. Their findings cast doubt about a strong and positive effect of marketing efforts on physician prescription 
behavior as evidenced in studies using aggregate and individual-level data. Parsons and Vanden Abeele (1981) find that physician prescription behavior is quite unresponsive to marketing efforts by pharmaceutical firms to the physician, and sales calls may even have a negative effect. Rosenthal, et al. (2003) did not find robust and significant effects for detailing at the individual brand level.

To the best of our knowledge, there has been no prior research that examines the effect of marketing efforts on sample-dispensing behavior by the physician. The most useful research for our purposes is probably the sparse literature in medicine that examines the motives physicians have when dispensing free samples to their patients. Motives that have been cited are: (1) financial savings for patients; (2) convenience; (3) initiate therapy immediately; (4) demonstrate the appropriate use to patients; (5) adjust prescribed doses before the full prescription is purchased; (6) evaluate early effectiveness or adverse effects (Chew, et al. 2000; Duffy and Clark 2003).

\subsection{Effects of patient requests on physician prescription and sample-dispensing behavior}

Most of the research that studies the effects of patient requests on physician decision-making is driven by the growing importance of direct-to-consumer advertising in the United States, mostly after the FDA's 1997 Draft Guidance on DTC broadcast advertisements. Direct-to-consumer advertising is an important driver of patient requests (Mintzes, et al. 2003), and scholars have only studied patient requests when triggered by direct-to-consumer advertising, rather than any other reason.

In a study using standardized patients that portrayed major depression, 27 percent of all patients requesting Paxil also received a prescription for it, 26 percent received an alternative antidepressant and 47 percent received no antidepressant, while only 3 percent of patients with the same condition were prescribed Paxil if they did not explicitly request Paxil (Kravitz, et al. 2005). Also in other settings, scholars found a positive relationship between patient requests and prescription (Kravitz, et al. 2003; Lyles 2002; Mintzes, et al. 2003) and physician referral (Kravitz, et al. 2003). This positive relationship is driven by patient pressure, and research has shown that when physicians do not comply with patient requests, patients are less satisfied with their physician visit (Kravitz, et al. 2003). 
Underlying typical studies in this area is the notion that patient requests - especially if triggered by direct-to-consumer advertising - are often for mild or trivial ailments (Weissman et al. 2004; Wilkes, Bell and Kravitz 2000). Kravitz, et al. (2003) found that subjective health distress predicted requests for physician services - referrals and prescriptions - more powerfully than did an objective count of chronic conditions, leading them to conclude that "requests may be driven more by anxiety than disease burden" (p. 1680). To the best of our knowledge, no research exists that examines the effect of patient requests on sample-dispensing by the physician.

\subsection{Moderating role of drug characteristics}

Even though prior research has stated that drug characteristics may moderate the above effects, their role in the effect of firms' marketing efforts and patients' requests on physician decision-making remains unexplored (Leeflang, Wieringa and Wittink 2004). While a drug can be characterized among many dimensions, such as its approved indications, its dosage, its potency, its administration method and frequency, its interactions with food and other drugs, its toxicity and its price, in this first exploratory study we will focus on two very salient product characteristics, namely the drug's effectiveness and the drug's side effects.

A drug's effectiveness is the extent to which the drug reduces the likelihood of negative clinical endpoints. A drug's side effects are secondary, and usually adverse, effects of a drug. For instance, for statins, a drug's effectiveness is the extent to which it reduces the likelihood of negative clinical endpoints, such as (fatal or non-fatal) myocardial infarction or coronary heart disease. The side effects statins may show are effects, such as gastro-intestinal reactions, headaches and nausea.

Above, we referenced prior literature that found positive informative and persuasive effects of firms' marketing efforts on physician decision-making. Now we explore the extent to which the effects of firms' marketing efforts on physician decision-making may depend upon the drug's effectiveness and side effects profile. When the firm promotes a more effective drug, as compared to a less effective drug, its ability to lower physician uncertainty about the drug and increase physicians' affect toward the drug is higher, as there will be stronger scientific evidence to back up the marketing effort (Azoulay 2002). The 
effect of the number of side effects on the relationship between a firm's marketing effort and a physician's decision-making is more speculative. On the one hand, a drug with many side effects creates a high level of physician uncertainty (e.g. on the interaction between all these side effects), which can be effectively reduced by firms' marketing efforts, while a drug with few side effects creates a low level of physician uncertainty, thus reducing the need for - and the return on - uncertainty reduction through firms' marketing efforts (Narayanan, Manchanda and Chintagunta 2003). On the other hand, it will be harder for firms to persuade physicians to treat patients with a drug that has a high number of side effects as compared to a drug with a low number of side effects. Hence, the total interaction effect of side effects and a firm's marketing efforts is difficult to predict ex ante, hence worthy of empirical investigation.

As to patient requests, we also referred to prior literature that found patient requests to occur more often for mild conditions. Thus, we expect that patient requests for drugs with many side effects are honored by the physician in fewer cases than patient requests for drugs with few side effects. The reason is that drugs with many side effects may easily do more damage to the patient than the damage from the initial mild condition (Kravitz et al. 2005). We expect that patient requests for drugs with higher effectiveness are honored by the physician in more cases than patient requests for drugs with lower effectiveness. On the one hand, a physician may react more positively to an effective drug request as s/he has less uncertainty about the drug's therapeutic value. On the other hand, a physician that reacts favorably to a patient request for an effective drug is more likely to receive favorable feedback afterwards than when he reacts favorably to a patient request for an ineffective drug. Given this feedback, the physician will increase his favorable reaction to patient requests, when it concerns the effective drug, and will decrease his favorable reaction to patient requests, when it concerns the ineffective drug.

Summarizing, we, a priori, expect that:

- Drug effectiveness may strengthen the effects of marketing efforts on prescription and sampling behavior by the physician.

- Drug effectiveness may strengthen the effects of patient requests on prescription and sampling behavior by the physician. 
- Side effects of a drug may weaken or strengthen the effects of marketing efforts on prescription and sampling behavior (depending upon information - persuasion tradeoff).

- Side effects of a drug may weaken the effects of patient requests on prescription and sampling behavior by the physician.

\subsection{Other variables}

We control for other variables, as well, that may affect prescription and sampling behavior. First, we control for the number of prescriptions and samples for competing brands in the prescription model, while we control for competitive samples in the sampling model. Based on Mizik and Jacobson (2004), we expect these effects may be positive or negative, without a clear ex ante expectation. They may be negative as prescriptions and samples for competing brands take away share of the focal brand (brand switching). They may also be positive, as increasing prescriptions and samples of competing brands can be indicative of growth in the drug category of the focal brand (category growth).

Second, we control for the effect of sample-dispensing of the own brand on prescriptions. This effect may be positive or negative, dependent upon the reason why the physician dispenses a sample (see above). Narayanan and Manchanda (2006) argue that a physician may dispense a sample, as s/he is uncertain about a patient's response to the focal drug. This would imply a negative contemporaneous effect of own samples on own prescriptions, as the sample comes at the expense of a prescription. On the other hand, Narayanan and Manchanda (2006) also argue that a physician may financially subsidize lowincome or low-coverage patients through sample-dispensing, in which case a drug prescription usually comes with a free sample. This would imply a positive contemporaneous effect.

Third, we control for carry-over effects, allowing these effects to interact with drug effectiveness and side effects. Physician persistence is an often observed phenomenon, driven by habit persistence and feedback of patients (Janakiraman, et al. 2005). We expect physician persistence to be more positive the more effective the drug is, as this will increase positive feedback of patients to the physician. On the other hand, the more side effects the drug has, the more negative feedback the physician will receive from patients, which in turn will lower physician persistence. 


\section{Data and Analysis}

\subsection{Data}

The datasets used for the empirical analysis in this study include a) physician-level panel data, b) drugapproval database and c) clinical trial reports. The physician-level monthly panel data ${ }^{2}$ span two years (Jan 2002-Dec 2003) and come from a large firm that specializes in pharmaceutical marketing. Due to confidentiality agreements, we cannot reveal the data source. The datasets contain information on three therapeutic categories, namely a) statins b) gastrointestinal \& coagulation drugs and c) erectile dysfunction (ED). The panel is a representative sample of physicians balanced across geographic regions, specialties and prescription volumes. Monthly brand-specific physician-level variables include total prescriptions written, total samples dispensed, total number of details, total number of meetings attended and total number of patient requests. These data are collected directly from the physician office through an electronic database that collects prescription and detailing-call information. Unlike previously researched databases, our database has information on samples dispensed by the physician, facilitating a more complete understanding of physician behavior across two key variables - prescriptions written and samples dispensed. These data are provided for three therapeutic categories. We calibrate our empirical model on the four most prescribed brands in each category. The shares of the focal brands are $85 \%$ in category $1,78 \%$ in category 2 and $88 \%$ in category 3 .

Our measures for drug characteristics, effectiveness and side effects were constructed as follows. We obtained the number of side effects from the drug-approval database from the FDA that includes not only a history of drug-application filing dates, approval dates, and drug-innovation classifications, but also a list of side effects that is periodically updated when new indications and/or side effects are announced.

We obtained drug effectiveness from a meta-analysis of clinical-trial reports (source: NICE). This meta-analysis provides a standardized measurement of effectiveness, namely a standardized Z-score

\footnotetext{
${ }^{2}$ Note that our physician-level database includes measures of marketing efforts and prescription data directly at the physician level. Due to institutional factors like availability of generics, insurance coverage, retail distribution etc., data collected at the pharmacy might not accurately reflect actual physician behavior. Since we have access to direct measures of physician-level variables, we can get a more accurate picture of effects of marketing activities on physician behavior.
} 
measure of the overall effectiveness of a brand relative to a placebo. Since these are standardized, the relative effectiveness of brands can be compared directly. The measurements are explained in full detail in the Appendix.

Table 1 provides the descriptive statistics and Pearson correlations for the variables of interest. Table 1 reflects variance in both the dependent variables of interest - i.e. prescriptions written (RX) and samples dispensed. The database includes all prescriptions within the examined drug categories that the panel of 2,774 physicians write in a total of 39,880 months of observations ${ }^{3}$. From Table 1 , we also observe that the correlations among the independent variables are small, hence attenuating multicollinearity problems in the analysis. No physician prescribes the same brand to all his/her patients.

\section{INSERT TABLE 1}

\subsection{Analysis}

This section describes the empirical model. We begin by specifying the econometric model and end this section with a discussion on the estimation procedure.

\subsubsection{Model}

To estimate the effects of marketing activities on two physician decision variables - a) prescriptions and b) samples dispensed - we describe our estimated econometric model below. Note that the model we specify - given the intricacies of the available data - is a descriptive model that does not allow normative claims (Franses 2005).

\subsubsection{Dependent Variables}

These include the total number of prescriptions (to new and previously diagnosed patients) written and total number of samples dispensed of brand $j$ at time $t$ by physician $p^{4}$. These are denoted as $R X_{j p t}$ and Samples $_{j p t}$ respectively.

\footnotetext{
${ }^{3}$ Our panel is an unbalanced panel as we do not observe all physicians in the panel for the complete data window, which is 24 months.

${ }^{4}$ Note that, while Gönül et al. (2001) and Mizik and Jacobson (2004) include samples offered by pharmaceutical representatives to physicians as predictor variables for physician-level prescriptions models, we model the effect of marketing activities on
} 


\subsubsection{Independent Variables}

As stipulated above, we study the effect of drug manufacturers' marketing efforts (through detailing and meetings) and patient requests on physician prescription and sample-dispensing decisions. Detailing effort by the manufacturer for brand $j$ at time $t$ to physician $p-$ denoted by Det $_{j p t}-$ is measured as the total number of detailing calls made by the sales force for brand $j$ to physician $p$ at time $t$. In similar spirit, we define and denote meetings as the number of meetings organized by the manufacturer for brand $j$ at time $t$ that were attended by physician $p$ - denoted by Meet $_{j p t}$ - and patient requests as the total number of patient requests for brand $j$ at time $t$ for physician $p$ - denoted by $R e q_{j p t}$. In order to accommodate carryover or inertia effects of marketing/non-marketing efforts as shown in Neslin (2001), we include a lagged prescriptions term in the conditional mean function.

As the markets we study include multiple competing brands, we also include prescriptions and samples dispensed for competing drugs for all major ( $=4$ top brands) brands in the drug category of brand $j$ to physician $p$ at time $t$, and denote these variables by CompRx $x_{j p t}$ and CompSamples $j p$.

Our main theoretical interest lies in understanding how drug characteristics (effectiveness and side effects) affect physicians' responsiveness to pharmaceutical firms' marketing efforts (detailing and meetings) and patient requests.

We include effectiveness of brand $j$, denoted by $E f f$, which is based on numerous scientific studies that compare the effectiveness of brand $j$ against a placebo. Consequently, a meta-analysis is conducted of an exhaustive set of studies $(100+)$ for each drug to generate a meta-analytic Z-score statistic, as compared to a placebo, yielding our measure, Eff .

We also include side effects of brand $j$ denoted by $S E_{j t}$, which is measured as the total number of side effects listed in the FDA- approved patient labeling for brand $j$ at time $t$. Note that as new side effects surface, the drug goes through the label-certification process and new side effects are added to the previous list; thus the list of side effects is time-varying. The average pair-wise overlaps across drugs for 
side effects for Category 1 through Category 3 are $0.77,0.81$ and 0.83 respectively. Thus, there is large overlap in side effects between drugs within a category, making a count of the number of side effects a valid measure. Also, while readers may think that newer drugs typically have fewer side effects than older drugs (creating a possible confound between number of side effects and the passing of time), this is not the case in our data. In fact, regressions of the number of side effects on time, show that the coefficient for time is insignificant.

The measures for effectiveness and side effects are also provided in more detail in Appendix 1. We include the main effects of the product characteristics and their interactions with all other variables posited above.

\subsubsection{Prescription model}

Equations (1-3) describe our physician prescription model. As argued above, physicians are influenced by drug characteristics. They are also influenced by manufacturers' marketing efforts (detailing and meetings) and patient requests for a drug. This influence may in turn depend upon the drug characteristics, as theorized above. Physician response to all these factors may also be heterogeneous across physicians. In addition, some physicians may write fewer or more prescriptions, due to unobserved characteristics, such as practice type, insurance network membership, specialty, etc. The latter effects are captured by the random physician specific intercept. We also accommodate unobservable physician-brand specific time varying factors via a stochastic error term $\xi_{p j t}^{r x} . \xi_{p j t}^{r x}$ is assumed to follow an IID multivariate

normal distribution while accounting for correlation across brands i.e. $\xi_{p t}^{r x} \sim N\left(0, \Sigma_{\xi}\right)$ where $\xi_{p t}^{r x}=\left\{\xi_{p j t}^{r x}\right\}$. Finally, competition is also included by accounting for prescriptions written and samples dispensed for competing drugs.

We specify a conditional model of physician specific prescriptions written, given physician specific marketing, product specific characteristics and patient requests. Given the count (integer nonnegative) data nature of our dependent variable (prescriptions written and samples dispensed) we specify a count-data based truncated regression model. In order to accommodate dispersion of the data we specify 
an NBD model as the base model while accommodating heterogeneity in physician responsiveness via a continuous mixture model. If significant differences between physicians persist in the parameters of the conditional distribution, the NBD model will be able to accommodate a wide degree of over-dispersion unlike the traditional Poisson count data model.

Our NBD distribution based conditional prescription models with parameter $\lambda_{\bullet}$ and overdispersion parameter $\alpha_{\bullet}$ is given by:

$$
\operatorname{Pr}\left(R X_{p j t}=k \mid \lambda_{p j t}^{r x}\right)=\frac{\Gamma\left(\alpha_{r x}+k\right)}{\Gamma\left(\alpha_{r x}\right) \Gamma(k+1)}\left(\frac{\alpha_{r x}}{\alpha_{r x}+\lambda_{p j t}^{r x}}\right)^{\alpha_{r x}}\left(\frac{\lambda_{p j t}^{r x}}{\alpha_{r x}+\lambda_{p j t}^{r x}}\right)^{k}
$$

where $R X_{p j t}$ is the number of new prescriptions of brand $j$ written by physician $p$ in month $t$. As the model parameter $\alpha_{\bullet}$ approaches infinity, the associated NBD distribution approaches the popular Poisson distribution. In order to ensure that $\lambda_{\bullet}$ is positive we employ a log-link function to parameterize each $\lambda_{\bullet}$ as a log function of variables including marketing, non-marketing and consumer driven variables like detailing, product characteristics and patient requests

$$
\lambda_{p j t}^{r x}=E\left[R X_{p j t} \mid x_{p j t}^{r x}\right]=\exp \left(x_{p j t}^{r x} \Theta^{r x}+\xi_{p j t}^{r x}\right)
$$

Where:

$$
\begin{aligned}
& \ln \left(\lambda_{p j t}^{r x}\right)=\beta_{p}^{r x}+\beta_{p j}^{r x}+\beta_{p 1}^{r x} S E_{j t}+\beta_{p 2}^{r x} E f f{ }_{j} \quad \text { (Non Marketing Effect) } \\
& +\left(\beta_{p 3}^{r x}+\beta_{p 4}^{r x} S E_{j t}+\beta_{p 5}^{r x} E f f_{j}\right) \text { Det }_{p j t} \quad \text { (Own Detailing Effect) } \\
& +\left(\beta_{p 6}^{r x}+\beta_{p 7}^{r x} S E_{j t}+\beta_{p 8}^{r x} E f f_{j}\right) \mathrm{Meet}_{p j t} \quad \text { (Own Meeting Effect) } \\
& +\left(\beta_{p 9}^{r x}+\beta_{p 10}^{r x} S E_{j t}+\beta_{p 11}^{r x} E f f{ }_{j}\right) \operatorname{Req}_{p j t} \quad \text { (Own Patient Request Effect) } \\
& +\theta_{p j}^{r x} \operatorname{CompRX}{ }_{p j t} \quad \text { (Competitive Prescriptions Effect) } \\
& +\kappa_{p j 1}^{r x} \text { Samples }_{p j t}+\kappa_{p j 2}^{r x} \text { CompSamples }{ }_{p j t} \quad \text { (Own and Competitive Samples Effect) } \\
& +\left(\phi_{p 1}^{r x}+\phi_{p 2}^{r x} S E_{j t}+\phi_{p 3}^{r x} E f f_{j}\right) \ln \left(R X_{p j, t-1}+1\right) \quad \text { (Inertia Effect) } \\
& +\xi_{p j t}^{r x} \quad \text { (Unobserved Demand Shifter) }
\end{aligned}
$$


The lagged log-prescriptions term, $\left(R X_{p j, t-1}+1\right)$ allows the effects of marketing and non-marketing variables in our model to influence not only the current period but also subsequent periods.

\subsubsection{Sample-dispensing model}

Equations (4-7) describe our sample-dispensing model, which is similar in philosophy to the prescription model shown above.

The sample-dispensing decision is also given by a NBD distribution as shown below:

$$
\operatorname{Pr}\left(\text { Samples }_{p j t}=k \mid \lambda_{p j t}^{s}\right)=\frac{\Gamma\left(\alpha_{s}+k\right)}{\Gamma\left(\alpha_{s}\right) \Gamma(k+1)}\left(\frac{\alpha_{s}}{\alpha_{s}+\lambda_{p j t}^{s}}\right)^{\alpha_{s}}\left(\frac{\lambda_{p j t}^{s}}{\alpha_{s}+\lambda_{p j t}^{s}}\right)^{k}
$$

where Samples ${ }_{p j t}$ is the number of samples dispensed of brand $j$ written by physician $p$ in

month $t$. Like the prescription model, in order to ensure that $\lambda^{s}$. is positive we employ a log-link function to parameterize each $\lambda^{s}$. as a log function of variables including marketing, non-marketing and consumer driven variables like detailing, product characteristics and patient requests

$$
\lambda_{p j t}^{s}=E\left[\text { Samples }_{p j t} \mid x_{p j t}^{s}\right]=\exp \left(x_{p j t}^{s} \Theta^{s}+\xi_{p j t}^{s}\right)
$$

where:

$$
\begin{aligned}
\ln \left(\lambda_{p j t}^{s}\right) & =\beta_{p}^{s}+\beta_{p j}^{s}+\beta_{p 1}^{s} S E_{j t}+\beta_{p 2}^{s} E_{j} & & \text { (Non Marketing Effect) } \\
& +\left(\beta_{p 3}^{s}+\beta_{p 4}^{s} S E_{j t}+\beta_{p 5}^{s} E_{j}\right) \mathrm{Det}_{p j t} & & \text { (Own Detailing Effect) } \\
& +\left(\beta_{p 6}^{s}+\beta_{p 7}^{s} S E_{j t}+\beta_{p 8}^{s} E_{j}\right) \mathrm{Meet}_{p j t} & & \text { (Own Meeting Effect) } \\
& +\left(\beta_{p 9}^{s}+\beta_{p 10}^{s} S E_{j t}+\beta_{p 11}^{s} E_{j}\right) \mathrm{Req}_{p j t} & & \text { (Own Patient Request Effect) } \\
& +\theta_{p j}^{s} \text { CompSamples }_{p j t} & & \text { (Competitive Samples Effect) } \\
& +\left(\phi_{p 1}^{s}+\phi_{p 2}^{s} S E_{j t}+\phi_{p 3}^{s} \text { Eff }_{j}\right) \ln \left(\text { Samples }_{p j, t-1}+1\right) & & \text { (Inertia Effect) } \\
& +\xi_{p j t}^{s} & & \text { (Unobserved Demand Shifter) }
\end{aligned}
$$

\subsubsection{Estimation procedure}


We employ Gibbs sampling with data augmentation (see Tanner and Wong (1987)) to simultaneously estimate the parameters of the prescriptions and sample dispensing models. If $\boldsymbol{\Xi}^{r x}, \boldsymbol{\Xi}^{s}$ denote the parameter vectors for the prescriptions written and samples dispensing models, the joint likelihood model is given by:

$$
\begin{aligned}
& f\left(\left\{\boldsymbol{\Xi}^{r x}, \boldsymbol{\Xi}^{s}\right\},\left\{\xi_{p j t}^{r x}\right\},\left\{\xi_{p j t}^{s}\right\}, \Sigma_{\xi^{x x}}, \Sigma_{\xi^{s}} \mid\left\{R X_{p j t}\right\}\left\{\text { Samples }_{p j t}\right\}\right) \\
& \propto \prod_{p, t, j} \operatorname{Prob}\left(R X_{p j t} \mid \text { Samples }_{p j t},\left\{\boldsymbol{\Xi}^{r x}\right\}, \xi_{p j t}^{r x}\right) \\
& \times \operatorname{Prob}\left(\text { Samples }_{p j t} \mid\left\{\mathbf{\Xi}^{r x}\right\},\left\{\boldsymbol{\Xi}^{s}\right\}, \xi_{p j t}^{r x}, \xi_{p j t}^{s}, \Sigma_{\xi^{s}}\right) \\
& \times \prod_{1}\left(\boldsymbol{\Xi}^{r x} \mid \overline{\boldsymbol{\Xi}}^{r x}, \Sigma^{r x}\right) \\
& \times \prod_{2}\left(\xi_{p j t}^{r x} \mid \Sigma_{\xi^{r x}}\right) \\
& \times \prod_{3}\left(\boldsymbol{\Xi}^{s} \mid \overline{\boldsymbol{\Xi}}^{s}, \Sigma^{s}\right) \\
& \times \prod_{4}\left(\xi_{p j t}^{s} \mid \Sigma_{\xi^{s}}\right) \\
& \times \prod_{5}\left(\overline{\boldsymbol{\Xi}}^{r x}, \Sigma^{r x}, \overline{\boldsymbol{\Xi}}^{s}, \Sigma^{s}, \Sigma_{\xi^{x x}}, \Sigma_{\xi^{s}}\right)
\end{aligned}
$$

The Gibbs sampling method allows us to generate a sequence of draws from the full conditional distributions for each group of parameters conditional on all other parameters. Interested readers may refer to Tanner and Wong (1987) for more details on this method. The data augmentation method greatly simplifies the introduction of $\xi$ 's in the prescription and samples dispensing models and simulation draws for $\Sigma_{\xi^{\prime x}}$ and $\Sigma_{\xi^{s}}$ as well as $\left\{\boldsymbol{\Xi}^{r x}, \boldsymbol{\Xi}^{s}\right\}$. By a process of iteration over all groups of parameters we obtain the joint posterior distribution shown above. Our estimation approach is similar to the one employed by Dong, Manchanda and Chintagunta (2005).

\section{Results}

This section discusses the results we obtained from the model estimation discussed above. We first discuss the model fit. Then we discuss the estimates of the model.

\subsection{Model fit}

We refer to the full model we specified in equations (1)-(7) as model 7 and find it outperforms six alternative models, both in terms of in-sample fit and out-of-sample prediction. 
Models 1 through 4 are nested models that have a simpler structure, because they only include a subset of all variables or do not include interaction effects. Model 1 includes detailing, meetings, patient requests and competition only. Model 2 also includes product characteristics, in addition to all variables in model 1. Model 3 also includes all interaction effects of detailing, meetings and patient requests with product characteristics, in addition to all variables in model 2. Model 4 includes dynamics through the inclusion of the one-period lagged values of the dependent variable, in addition to all variables in model 3.

Model 5 and 6 are added to test for the validity of specific concerns regarding the inclusion of endogenous independent variables in our model and the conceptualization upon effectiveness and side effects of a drug. The first concern is that we include an endogenous variable (samples dispensed by physician) as an explanatory variable in the prescription equation. One may wonder whether the model fit is improved if one were to omit such endogenous variables from the model. The results for model 5 (see Tables 2 and 3 ) indicate that this is not the case.

The second concern is that effectiveness and side effects may actually both be part of a concept that is "net effectiveness" of a drug. Therefore, we estimate model 6 that includes net effectiveness defined as the difference between effectiveness and the number of side effects for each brand - and find it to have a lower fit and predictive ability, as compared to model 7.

In addition to these concerns, one may also wonder to what extent the joint estimation improves model fit. To examine this issue, we have estimated the prescription and samples model, both separately (see Table 2) and simultaneously (see Table 3). While it is easier to estimate the two models separately, the results show that separate estimation does come at the cost of loss in statistical efficiency, as compared to joint estimation.

The most appropriate model is therefore, Model 7, in which the prescription and the sampledispensing equations are estimated jointly. This model shows a satisfactory fit. Also, the conclusions based on the estimates of model 7 are in line with what one would conclude from the pattern of results of the six other models. Also note again that our model accounts for physician-specific response 
heterogeneity as done in Dong, Manchanda and Chintagunta (2005) ${ }^{5}$. Finally, note that we also estimated these models category-by-category and obtained very similar results. Thus, our results are not sensitive to differences in effectiveness and side effect profiles across categories.

\section{INSERT TABLE 2 \& TABLE 3}

\subsection{Estimates}

We discuss the estimates depicted in Tables 4 to 6 , as follows. As the interpretation of the main effects is complicated by the many interaction terms in the model, we first calculate the marginal effects of our focal variables - marketing efforts and patient requests - on physicians' prescription and sampledispensing behavior (Table 4). We then turn to the estimates of the full model (see Tables 5a, 5b, 6a, 6b), in which we first focus on the interaction effects of marketing efforts and product characteristics on physicians' prescription and sampling behavior, and second the interaction effects of patient requests and drug characteristics on physicians' prescription and sampling behavior. We end with a discussion on other effects we controlled for in our model, such as carry-over effects of prescriptions and samples, and competitive effects.

\section{INSERT TABLE 4}

\subsubsection{Marginal effects of marketing efforts to physicians and patient requests}

Table 4 shows the marginal effects of the variables of focal interest. From Table 4, the result that stands out the most is that the effects of manufacturers' marketing efforts to physicians and patient requests on prescriptions are heterogeneous across brands. This is also the case with the marginal effects of patient requests on samples dispensed. We find that detailing has a positive effect on prescriptions for 7 out of the 12 brands, while it has a positive effect on sample-dispensing by physicians for all 12 brands. Meetings

\footnotetext{
${ }^{5}$ The Dong, Manchanda and Chintagunta (2005) study focuses more on demonstrating the gains from targeted detailing (no sampling behavior is modeled) under the assumption of profit maximizing firms. This study focuses instead on the interplay between sampling and prescriptions written and the moderating effect of product characteristics on physician behavior. Since samples given to physicians is unobserved in our data, modeling the demand side accounting for interplay between samples dispensed and Rx, while simultaneously modeling the supply side, is beyond the scope of the current research study, but worthy of future research.
} 
have a positive effect on prescriptions for 7 out of the 12 brands, of which 6 are the same brands for which we found detailing to be effective. Meetings have a positive effect on the number of samples the physician hands out for all brands. Thus, we find that: (1) detailing and meetings are generally effective or ineffective for the same brands, (2) detailing and meetings have negative effects on prescriptions written by physicians for some brands; (3) detailing and meetings have positive effects on sample-dispensing by physicians for all brands; (4) meetings have stronger effects on prescription behavior than detailing.

We also find that the marginal effect of patient requests on prescription behavior is positive for 10 out of 12 brands, while its effect on sample-dispensing behavior is positive for only 8 brands out of 12 . Moreover, while patient requests for certain brands may positively affect prescription behavior, they do not necessarily affect sample-dispensing behavior for that brand positively (and vice versa).

The focus of the present paper lies in explaining this heterogeneity across brands we find, along two drug characteristics, namely drug effectiveness and side effects. We first turn to the interaction effects of these product characteristics with manufacturers' marketing efforts to physicians, after which we turn to the interaction effects of these product characteristics with patient requests. These estimates are depicted in Tables 5 and 6. In these Tables, we report the posterior means for the model parameters. We also report a posterior probability - denoted as $\rho$ - between brackets, which is the probability that parameters are less than or greater than zero.

\section{INSERT TABLES 5A, 5B, 6A and 6B}

\subsubsection{Interaction effects of marketing actions to physicians and drug characteristics}

As shown in the first part of Table 5a, we find that detailing has a more positive effect on prescriptions for more effective drugs, as compared to less effective drugs $(\beta=0.381, \rho=1.00)$, and for drugs with more side effects, as compared to drugs with fewer side effects $(\beta=0.023, \rho=0.98) .{ }^{6}$ While we find similar results for the interaction effects of meetings with drug effectiveness and side effects, we also find that the posterior probabilities are relatively low $(\rho=0.83$, respectively 0.81$)$.

\footnotetext{
${ }^{6}$ Note that effective drugs are not necessarily detailed more. In fact, the correlation between effectiveness and detailing is 0.26 .
} 
For the sampling equation (see Table 6a), we find that the interaction effect of drug effectiveness with detailing is positive, as expected, but very weak $(\beta=0.001 ; \rho=0.84)$. The other interaction effects between marketing efforts and drug characteristics are significant and positive as expected. We find that meetings have a more positive effect on samples dispensed for more effective drugs, as compared to less effective drugs $(\beta=1.741 ; \rho=1.00)$. We also find that both detailing $(\beta=0.015 ; \rho=1.00)$ and meetings $(\beta=0.061 ; \rho=0.96)$ have a more positive effect on sample-dispensing for drugs with more side effects, as compared to drugs with less side effects.

The findings above fit our theoretical expectations, namely that: (1) marketing efforts have a more positive effect on prescriptions written and samples dispensed by physicians for more effective drugs, as compared to less effective drugs (probably because pharmaceutical firms and their representatives can present more sound scientific evidence for more effective drugs); (2) marketing efforts have a more positive effect on prescriptions written and samples dispensed by physicians for drugs with more side effects, as compared to drugs with fewer side effects (thus supporting the effect of detailing calls on physician-uncertainty reduction on the side effect profile).

\subsubsection{Interaction effects of patient requests and drug characteristics}

As expected, we find that patient requests have a more positive effect on prescriptions $(\beta=0.131$; $\rho=1.00)$ and samples dispensed $(\beta=0.630 ; \rho=1.00)$ for relatively more effective drugs, as compared to less effective drugs. This fits our ex ante expectation that physicians will be more inclined to honor a patient's request when the patient requests a more effective drug, than when this is not the case.

Also as expected, we find that patient requests have a more negative effect on prescriptions $(\beta=-$ $0.029 ; \rho=0.99)$ and samples dispensed $(\beta=-0.198 ; \rho=1.00)$ for drugs that have more side effects, as compared to drugs with less side effects. As we cited earlier, the reason may be that drugs with many side effects may do more harm than good to the patient, especially as prior research has indicated that patient requests may often be for questionable, rather than clear, medical indications (Kravitz et al. 2005; Wilkes, Bell and Kravitz 2000). Drugs with many side effects may actually lead to more severe conditions caused by the side effects than the mild condition the drug was to treat in the first place. 


\subsubsection{Other effects}

Own carry-over effects. The own carry-over effects are positive in both the prescription model $(\phi=$ $2.476 ; \rho=1.00)$ and the sample dispensing $(\phi=18.311 ; \rho=1.00)$ model, as expected. This finding points at strong inertia in physician behavior. This carry-over effect increases with effectiveness $(\phi=0.116 ; \rho=$ $1.00)$ in the prescriptions model, though only marginally so in the sample dispensing model $(\phi=0.009 ; \rho$ $=0.59$ ). More effective drugs are more likely to provide favorable clinical feedback to the physician, increasing the number of prescriptions of the drug the physician will write. However, if the main reason of sampling for the physician is to try the drug, there is no reason to expect positive clinical feedback to positively affect future sampling. Drugs with many side effects have smaller carry-over effects, both in the prescriptions model $(\phi=-0.032 ; \rho=1.00)$ and in the sample dispensing model $(\phi=-0.299 ; \rho=1.00)$, probably because patients are more likely to need to quit treatment because of the appearance of side effects.

Competitive effects. As presented in Table $5 \mathrm{~b}$ and $6 \mathrm{~b}$ (which serve as examples of these effects for one category, i.e. statins; full results for the other categories are available in a Technical Note that can be requested from the authors), the effects of competitive prescriptions on own prescriptions are positive and highly significant. The same is the case for the effects of competitive samples on own samples. The competitive effects are the product of two contrary phenomena. One (negative) effect may be brandswitching (Mizik and Jacobson 2004), while the other (positive) effect may be category growth (Berndt et al. 1995). Our findings hint that the latter is more dominant (explaining its positive sign). Our competitive effects are very similar to those found by Mizik and Jacobson (2004), even though they used a different methodology. We also applied the Mizik and Jacobson (2004) methodology to our data (modeling main effects only, without product characteristics $)^{7}$. When doing this, we find similar competitive patterns.

\footnotetext{
${ }^{7}$ Note that neither product characteristics nor the interactions of product characteristics with the other independent variables can be included when using the Mizik and Jacobson (2004) methodology, as these effects cannot be identified in a brand-by-brand analysis.
} 
Effect of Samples on Prescriptions. In our prescription model, we also control for the effect samples both own samples and competitive samples - dispensed may have on prescriptions given. These effects are presented in Table 5b, again only for the statins category (we report similar findings in full detail for the other categories again in the Technical Note, mentioned above). We find that competitive samples generally have a negative effect on own prescriptions. More counterintuitive at first is that the contemporaneous effect of own samples on own prescriptions is positive. This may be due to the common practice in the United States also to provide a sample when a prescription is written.

\subsubsection{Elasticities of Drug Characteristics}

In order to assess the cost of side effects and benefits from improved effectiveness, we illustrate the computation of the mean own-detailing elasticity across all physicians for both side effects and effectiveness. From Table 7, we can see that it takes $1.71 \%$ less detailing effort from the current detailing level to maintain the current level of prescription of Brand 1 in category 2, if it were to improve its effectiveness by $1 \%$. For the same drug, it would take a drop of detailing by $1.42 \%$ from current levels to maintain the same amount of samples dispensed, given a $1 \%$ increase in effectiveness.

Also from Table 7 , we can see that a $.80 \%$ increase in detailing from current detailing level is required for brand 1 in category 1 to maintain current prescription shares, if there is a $1 \%$ increase in the number of side effects. Similarly it takes $1.19 \%$ increase in detailing from current detailing levels to maintain current levels of samples dispensing, if there is a $1 \%$ increase in the number of side effects.

These effects vary by brand and category. Much like the tradeoff with side effects, the compensatory nature of detailing with higher levels of effectiveness of a drug varies by brand and category. Our results therefore provide empirical support for asymmetric effects of detailing effort as a result of improved effectiveness or additional side effects. The Technical Note mentioned above also contains the mean own-meeting and own-patient requests elasticities, again across all physicians for both side effects and effectiveness. 


\section{Discussion}

This section first summarizes our findings. Second, we develop implications for managers and regulators from our findings. Third, we discuss the study's limitations and develop directions for future research.

\subsection{Summary of findings}

We asserted at the onset of this paper that prior literature has found mixed effects of firms' marketing efforts on physicians' prescription behavior. We posit in this paper that one reason why this may happen is that physicians' response to marketing efforts may actually depend upon drug characteristics, such as a drug's effectiveness and side effects. We also posit that such drug characteristics may also moderate the effect of "influencers" other than marketing efforts - such as patient requests - on drug decisions by physicians other than prescribing - such as sample-dispensing by physicians.

Our most important findings are as follows. First, we find that the effects of marketing efforts and patient requests on physician prescription behavior do indeed vary by brand. For some brands, marketing efforts and patient requests are positively affecting physician prescribing behavior; but for other brands, these effects are negative. A similar pattern occurs for the effects of patient requests on sample-dispensing behavior. Second, we find that physicians' reactions to firm's marketing efforts and patient requests may be different in prescription behavior, as compared to their reaction in sample dispensing behavior. Third, we find that drug characteristics - such as effectiveness and side effects - moderate the response by physicians to both marketing efforts and detailing, both in their prescription and their sampling behavior. Physicians tend to respond with more prescriptions or samples to firms' marketing efforts when the drug is more effective or has more side effects. They respond to patient requests with more prescriptions or samples when it concerns more effective drugs, as compared to less effective drugs, or drugs with fewer side effects, as compared to more side effects. Fourth, we find that there is substantial persistence in physician decision-making. 


\subsection{Implications for managers and regulators}

Our empirical findings provide valuable insights for practice, both for managers of pharmaceutical firms and for public policy administrators. First, our results show that firms' marketing efforts are effective for some drugs, while they are counterproductive for others, dependent upon the characteristics (such as effectiveness and side effects) of the drugs. Marketing effort is more likely to have positive effects on physicians' decision-making behavior if the marketing effort is supporting an effective drug or a drug with many side effects, as compared to an ineffective drug or a drug with few side effects. Thus, while Mizik and Jacobson (2004) showed that physicians are not necessarily "easy marks", we show that they also "carefully weigh what they hear" both from firms and patients. As the prime need of physicians is information for which the manufacturer can be a useful source, public policy could actively restrict detailing to its pure informative role. Restricting the number of visits and further curtailing gift-giving are options one could consider. For managers, it supports the call for more evidence-based marketing. Firms' marketing efforts should not only be structured according to market size (= the number of patients suffering from a condition), but also according to the evidence that exists to support effectiveness and the side effects profile of a drug.

Second, we see that physicians seem to be as thoughtful about drug characteristics in their sampling behavior as in their prescription behavior. Thus, there is no reason to differentiate policies for detailing from policies for sampling dispensing behavior. For instance, several European governments consider to curtail, in same cases completely ban, sampling by physicians, while they do allow detailing. To managers, this also underlines that stimulating sample-dispensing by physicians (either by increasing sample supply or other marketing activities) needs to be considered with the same caution (towards drug characteristics) as marketing actions that aim to stimulate prescription behavior.

Third, we find that patient requests also do not automatically lead either to sampling or prescription by physicians. For some brands, patient requests may actually lower the number of prescriptions or samples. As patient requests are often triggered by direct-to-consumer advertising, this shows that prior authors may actually have overstated the damage done to public health by direct-to- 
consumer advertising (Hollon 2005). Physicians do consider the side effect profile of a drug in sampling and prescription decisions upon patient request, while they also hold into account the effectiveness of the drug in the sampling decision upon patient request. For managers, the most important lesson learned is that triggering patient requests will have a higher return on investment for drugs with fewer side effects than for drugs with more side effects. This is exactly opposite to the return on investment on marketing efforts to physicians, which will be higher for drugs with more side effects, than for drugs with fewer side effects.

Fourth, we find substantial evidence of physician persistence. This result (Janakiraman, et al. 2005) underlines that changing physician habits may be challenging.

\subsection{Limitations and directions for future research}

As this paper is the first empirical examination of the moderating role of drug characteristics in physician responsiveness to marketing effort and patient requests, it is easy to point at some limitations, which may generate fruitful future research. First, we do not have data on patient conditions. Obviously, treatment choice not only depends on drug characteristics, but also the patient's condition. Information on patients' medical files is the obvious omission from most studies of prescription behavior (for privacy concerns). Research that studies the influence of patients' medical histories on physician (e.g. prescription and sampling) and patient (e.g. compliance) behavior promises to be very impactful.

Second, we only examine the role of two product characteristics (effectiveness and side effects) and two marketing efforts (detailing and meetings) of firms. While extending our model to allow for other product characteristics and marketing efforts is straightforward, research extending our study in this direction may prove to bear new conceptual insights. Moreover, our measure for side effects is the number of side effects and not the severity of side effects. As far as we know, there is no information available on the severity of side effects that is consistently reported across brands and across clinical studies.

Third, while we find physician response heterogeneity, we do not identify the source of it. Future research identifying why physicians respond differently may be insightful. Physician characteristics one 
may examine in such a study are specialty, practice size, location, health coverage by patient base, and group versus individual practice.

Fourth, we do not have data on the stock of samples, our panel of physicians have at their disposal, nor do we have data on the sample-dispensing behavior of the pharmaceutical firm towards the physicians in our panel. Therefore, the results of the physician sample-dispensing equation need to be interpreted with caution as our estimates may be sensitive to omitted variable bias.

\section{Envoy}

A strong debate has surged on physician responsiveness to firms' marketing efforts and patient requests. Both pharmaceutical firms and public policy makers are actively involved in the debate. We hope that this paper triggers more balanced research on this issue, accounting for heterogeneous reactions across drugs. 


\section{References}

Azoulay, Pierre (2002), "Do Pharmaceutical Sales Respond to Scientific Evidence?" Journal of Economics and Management Strategy, 11 (4), 551-594.

Becker, G. and K. Murphy (1993). "A Simple Theory of Advertising as a Good or Bad," Quarterly Journal of Economics 108, 941-963.

Berndt, Ernst R., Linda T. Bui, David H. Reiley and Glen L. Urban (1995), "Information, Marketing and Pricing in the U.S. Anti-Ulcer Drug Market," American Economic Review, 85 (2), 100-105.

Berndt, Ernst R., Linda T. Bui, David H. Reiley and Glen L. Urban (1997), "The Roles of Marketing, Product Quality and Price Competition in the Growth and Composition of the U.S. Anti-Ulcer Drug Industry," in: Timothy F. Bresnahan and Robert J. Gordon, eds., The Economics of New Products, Studies in Income and Wealth, 58 (Chapter 7), Chicago: University of Chicago Press for the National Bureau of Economic Research, 277-322.

Chew, Lisa D., Theresa S. O'Young, Thomas K. Hazlet, Katharine A. Bradley, Charles Maynard and Daniel S. Lessler (2000), "A Physician Survey of the Effect of Drug Sample Availability on Physicians' Behavior," Journal of General Internal Medicine, 15 (July), 478-483.

Chintagunta, Pradeep K. and Ramarao Desiraju (2005), "Strategic Pricing and Detailing Behavior in International Markets," Marketing Science, 24 (1), 67-80.

Dong, Xiaojing, Puneet Manchanda and Pradeep K. Chintagunta (2005), "Quantifying the Benefits of Individual Level Targeting in the Presence of Firm Strategic Behavior," University of Chicago, Working Paper.

Duffy, C.M. and M. Clark (2003), "Who Receives Free Sample Medications?" Journal of General Internal Medicine, 18 (April), 205.

Franses, Philip Hans (2005), "On the Use of Econometric Models for Policy Simulation in Marketing," Journal of Marketing Research, 42 (February), 4-14.

Gönül, Füsun F., Franklin Carter, Elina Petrova and Kannan Srinivasan (2001), "Promotion of Prescription Drugs and Its Impact on Physicians' Choice Behavior," Journal of Marketing, 65 (July), 79-90.

Grossman, G. and C. Shapiro (1984), "Informative Advertising with Differentiated Products,” Review of Economic Studies, 51, 63-81.

Hollon, Matthew F. (2005), "Direct-to-Consumer Advertising: A Haphazard Approach to Health Promotion," Journal of American Medical Association, 293 (16), 2030-2032.

Janakiraman, Ramkumar, Shantanu Dutta, Catarina Sismeiro, and Phil Stern (2005), "Are They All the Same? Physicians' Persistence and Its Implications for Marketing Communication," working paper.

Kravitz, Richard L., Robert A. Bell, Rahman Azari, Steven Kelly-Reif, Edward Krupat, David H. Thom (2003), "Direct Observation of Requests for Clinical Services in Office Practice: What Do Patients Want and Do They Get It?" Arch Intern Med, 163, 1673-1681.

Kravitz, Richard L., Ronald M. Epstein, Mitchell D. Feldman, Carol E. Franz, Rahman Azari, Michael S. Wilkes, Ladson Hinton, Peter Franks (2005), "Influence of Patients' Requests for Direct-to-Consumer Advertised Antidepressants," Journal of the American Medical Association, 293 (16), 1995-2002.

Leeflang, Peter, Jaap Wieringa and Dick Wittink (2004), "The Effects of Pharmaceutical Marketing on Sales of Prescription Drugs in the Netherlands," $6^{\text {th }}$ CU-Boulder Invitational Choice Symposium.

Leffler, Keith B. (1981), "Persuasion or Information? The Economics of Prescription Drug Advertising," Journal of Law and Economics, 24 (1), 45-74.

Lyles, Alan (2002), "Direct Marketing of Pharmaceuticals to Consumers," Ann. Rev. Public Health, 23, 73-91.

Manchanda, Puneet and Pradeep K. Chintagunta (2004), "Responsiveness of Physician Prescription Behavior to Salesforce Effort: An Individual Level Analysis," Marketing Letters, 15 (2-3), 129-145.

Manchanda, Puneet, Peter E. Rossi and Pradeep K. Chintagunta (2004), "Response Modeling with Nonrandom Marketing-Mix Variables," Journal of Marketing Research, 41 (November), 467-478. 
Mintzes, Barbara, Morris L. Barer, Richard L. Kravitz, Ben Bassett, Joel Lexchin, Arminée Kazanjian, Robert G. Evans, Richard Pan, Stephen A. Marion (2003), "How Does Direct-to-Consumer Advertising (DTCA) Affect Prescribing? A Survey in Primary Care Environments With and Without Legal DTCA,” CMAJ, 169 (5), 405-412.

Mizik, Natalie and Robert Jacobson (2004), “Are Physicians 'Easy Marks'? Quantifying the Effects of Detailing and Sampling on New Prescriptions," Management Science, 50 (12), 1704-1715.

Morelli, D. and M.R. Koenigsberg (1992), "Sample Medication Dispensing in a Residency Practice," Journal of Family Practice, 34, 42-48.

Narayanan, Sridhar (2004), "Heterogeneous Learning and the Targeting of Marketing Communication for New Products," working paper.

Narayanan, Sridhar, Ramarao Desiraju and Pradeep K. Chintagunta (2004), "Return on Investment Implications for Pharmaceutical Promotional Expenditures: The Role of Marketing-Mix Interactions," Journal of Marketing, 68 (October), 90-105.

Narayanan, Sridhar, Puneet Manchanda, and Pradeep K. Chintagunta (2005), "Temporal Differences in the Role of Marketing Communication in New Product Categories," Journal of Marketing Research, 42 (August), 278-290.

Narayanan, Sridhar and Puneet Manchanda (2006), "The Role of Free Samples in the Pharmaceutical Industry: An Empirical Analysis," 2006 Informs Marketing Science Conference, University of Pittsburgh.

Neslin, Scott (2001), "ROI Analysis of Pharmaceutical Promotion," unpublished study conducted for the Association of Medical Publications available at http://www.rappstudy.org.

Parsons, Leonard Jon and Piet Vanden Abeele (1981), "Analysis of Sales Call Effectiveness," Journal of Marketing Research, 18 (February), 107-113.

Rizzo, John A. (1999), "Advertising and Competition in the Ethical Pharmaceutical Industry: The Case of Antihypertensive Drugs," Journal of Law and Economics, 42 (1), 89-116.

Rosenthal, Meredith B., Ernst R. Berndt, Julie M. Donohue, Arnold M. Epstein, and Richard G. Frank (2003), "Demand Effects of Recent Changes in Prescription Drug Information," Frontiers in Health Policy Research, 6, 1-26, David M. Cutler and Alan M. Garber (eds.), MIT Press.

Tanner, M.A. and W.H. Wong (1987), "The Calculation of Posterior Distributions by Data Augmentation," Journal of the American Statistical Association, 82, 528-549.

Weissman, Joel S., David Blumenthal, Alvin J. Silk, Michael Newman, Kinga Zapert, Robert Leitman, and Sandra Feibelmann (2004), "Physician Report on Patient Encounters Involving Direct-toConsumer Advertising," Health Affairs, April 28, W4/219-W4/233.

Wilkes, Michael S., Robert A. Bell, and Richard L. Kravitz (2000), "Direct-to-Consumer Prescription Drug Advertising: Trends, Impact and Implications," Health Affairs, 19 (2), 110-128. 


\section{APPENDIX: Measurements}

This appendix details how our measures for effectiveness and side effects were constructed.

\section{Effectiveness of Drug}

The National Institute for Health and Clinical Excellence (NICE) publishes assessment reports, in which it meta-analyzes clinical-trial reports provided by manufacturers and/or other scientific evidence, in which a brand (chemical-dosage pair) is compared with other drugs of similar/dissimilar dosage levels, 'usual' care (or the standard treatment), no treatment or a placebo. The sources it uses to collect these reports are: Medline, EMBASE, Cochrane Database of Systematic Reviews (CDSR), Cochrane Central Register of Controlled Trials (CCTR), Database of Abstracts of Reviews of Effects (DARE), Science Citation Index, NHS Economic Evaluation Database (NHS EED), Health Technology Assessment Database (NHS HTA) and CINAHL.

It portrays all drugs in a category on multiple effectiveness dimensions, as compared to a placebo treatment. We selected the most salient effectiveness dimensions in each of our product categories, namely: for statins (all-cause mortality, cardiovascular disease, coronary heart disease mortality, stroke mortality, and other cardiovascular events), for gastro intestinal drugs (gastric acidity, gastric emptying, progesterone effect, food effects, absorption and metabolite desethyloxybutynin) and for erectile dysfunction drugs (geriatrics, renal insufficiency, hepatic insufficiency, blood pressure, and erectile response).

The effectiveness measures are generated by NICE by employing the following steps.

Step 1- Suppose $\mathrm{T}_{\mathrm{BA}}$ is the result of direct comparison of intervention $\mathrm{B}$ versus $\mathrm{A}$ (which is the placebo in our case), and $\mathrm{T}_{\mathrm{CA}}$ is the direct comparison of intervention $\mathrm{C}$ versus $\mathrm{A}$. Then the estimate of the adjusted indirect comparison of intervention $\mathrm{B}$ versus $\mathrm{C}\left(\mathrm{T}^{\prime}{ }_{\mathrm{BC}}\right)$ is calculated by $\mathrm{T}^{\prime}{ }_{\mathrm{BC}}=\mathrm{T}_{\mathrm{BA}}-\mathrm{T}_{\mathrm{CA}}$ and its standard error is $\mathrm{SE}\left(\mathrm{T}^{\prime}{ }_{\mathrm{BC}}\right)=\sqrt{ }\left(\mathrm{SE}\left(\mathrm{T}_{\mathrm{BA}}\right)^{2}+\mathrm{SE}\left(\mathrm{T}_{\mathrm{CA}}\right)^{2}\right)$ where $\mathrm{SE}\left(\mathrm{T}_{\mathrm{BA}}\right)$ and $\mathrm{SE}\left(\mathrm{T}_{\mathrm{CA}}\right)$ are the standard errors of $\mathrm{T}_{\mathrm{BA}}$ and $\mathrm{T}_{\mathrm{CA}}$ respectively.

Step 2 - To overcome the problem of differing sample sizes and demographics across studies, a metaanalysis is conducted of an exhaustive set of studies (100+) to generate a meta-analytic Z-Score statistic for each drug, compared to placebo treatment, which we denote as $E f f j$.

We then average these Z-scores across effectiveness dimensions to generate our standardized measure $E f f f_{j}$ which is the composite standardized measure (relative to placebo) of effectiveness of Drug $j$.

\section{Side Effects of Drug}

Clinical-trial reports provided by manufacturers to regulators and government-approved product labels list all discovered side effects for each brand. Our measure of side effectiveness of each drug is a count of the total number of the side effects listed across both these sources for each brand (source: FDA).

Table A1 provides an overview of all side effects of all drugs in our sample. 
Table A1: Overview of All Potential Side Effects in our Sample

\begin{tabular}{ccc}
\hline Statins & Gastrointestinal \& Coagulation & Erectile Dysfunction (ED) \\
\hline Insomnia & & Angina pectoris \\
Angioedema & Insomnia & Back-pain \\
Anorexia & Angioedema & Dizziness \\
Asthenia & Anorexia & Headache \\
Peripheral neuropathy & Asthenia & Indigestion \\
Alopecia & Peripheral neuropathy & Muscle-aches \\
Pruritus & Alopecia & Flushing \\
Chest pain & Pruritus & Stuffy/Running nose \\
Hypoglycemia & Rash & Abnormal Vision \\
Hyperglycemia & Jaundice & Nausea \\
Thrombocytopenia & Pancreatitis & Impotence \\
Dysaesthesia & Lupus & Chest pain \\
Hypoesthesia & Erythematosus & \\
Fatigue & Dizziness & \\
Polyneuropathy & Proteinuria & \\
Hepatitis & Gastro esophageal reflux disease & \\
Fulminant hepatic necrosis & Peptic ulcer disease & \\
Jaundice & Irritable bowel syndrome & \\
Pancreatitis & Ulcerative colitis (UC) & \\
Lupus & & \\
Erythematosus & & \\
Dizziness & & \\
Pneumonia sepsis & & \\
\hline
\end{tabular}


Table 1: Descriptive Statistics and Correlation Table

\begin{tabular}{|c|c|c|c|c|c|c|c|c|c|c|c|}
\hline \multicolumn{5}{|c|}{ Descriptive Statistics } & \multicolumn{7}{|c|}{ Correlation Table } \\
\hline$\overline{\text { Variable }}$ & Mean & Std. Dev & Min & $\operatorname{Max}$ & Prescriptions & Meeting & Detailing & $\begin{array}{c}\text { Patient } \\
\text { Request }\end{array}$ & $\begin{array}{c}\text { Competitive } \\
\text { Prescriptions }\end{array}$ & Samples & $\begin{array}{c}\text { Competitive } \\
\text { Samples }\end{array}$ \\
\hline Prescriptions & 1.23 & 1.86 & 0 & 51 & 1 & & & & & & \\
\hline Meeting & 0.02 & 0.17 & 0 & 18 & 0.05 & 1 & & & & & \\
\hline Detailing & 0.73 & 0.97 & 0 & 13 & -0.00 & 0.04 & 1 & & & & \\
\hline Patient Request & 0.07 & 0.48 & 0 & 41 & 0.05 & 0.00 & -0.02 & 1 & & & \\
\hline Competitive Prescription & 3.69 & 3.94 & 0 & 80 & 0.36 & 0.01 & -0.03 & -0.03 & 1 & & \\
\hline Samples & 0.15 & 0.50 & 0 & 19 & 0.20 & 0.03 & -0.04 & -0.03 & 0.02 & 1 & \\
\hline Competitive Samples & 0.46 & 0.99 & 0 & 24 & 0.02 & 0.01 & 0.03 & 0.06 & 0.17 & 0.24 & 1 \\
\hline
\end{tabular}

Table 2: Model Selection and Out-of-Sample Tests

\begin{tabular}{lcccc}
\hline \multirow{2}{*}{ MODEL } & \multicolumn{2}{c}{ Prescription Model } & \multicolumn{2}{c}{ Sample-Dispensing Model } \\
\cline { 2 - 5 } & BIC & $\begin{array}{c}\text { Out-of-Sample } \\
\text { RMSE }\end{array}$ & BIC & $\begin{array}{c}\text { Out-of-Sample } \\
\text { RMSE }\end{array}$ \\
Model 1 & 611.23 & 6.451 & 513.45 & 4.333 \\
Model 2 & 527.19 & 4.368 & 464.01 & 4.018 \\
Model 3 & 481.36 & 3.411 & 419.22 & 3.848 \\
Model 4 & 416.94 & 2.006 & 398.68 & 3.476 \\
Model 5 & 513.51 & 4.017 & 415.66 & 3.451 \\
Model 6 & 486.45 & 3.622 & 412.31 & 3.794 \\
Model 7 & 309.47 & 1.015 & 350.00 & 2.972 \\
\hline
\end{tabular}

Table 3: Joint Model Selection and Out-of-Sample Tests

\begin{tabular}{lcc}
\hline \multicolumn{3}{c}{ Joint Estimation of Prescription and Sample-Dispensing Model } \\
\hline MODEL & BIC & Out-of-Sample RMSE \\
Model 1 & 648.44 & 8.117 \\
Model 2 & 559.38 & 6.446 \\
Model 3 & 481.11 & 5.967 \\
Model 4 & 459.23 & 5.001 \\
Model 5 & 407.67 & 4.946 \\
Model 6 & 400.13 & 4.784 \\
Model 7 & 389.96 & 4.595 \\
\hline
\end{tabular}


Table 4: Marginal Effects

\begin{tabular}{llcccccc}
\hline & \multicolumn{3}{c}{ Prescription Model } & \multicolumn{3}{c}{ Sample-Dispensing Model } \\
\hline Category & Brand & Detailing & Meeting & Patient Request & Detailing & Meeting & Patient Request \\
\hline 1 & Brand1 & 0.049 & 0.280 & -0.181 & 0.051 & 0.033 & 0.026 \\
1 & Brand2 & -0.068 & 0.255 & -0.021 & 0.037 & 0.052 & 0.019 \\
1 & Brand3 & 0.028 & 0.618 & 0.003 & 0.105 & 0.036 & 0.020 \\
1 & Brand4 & 0.016 & 0.490 & 0.032 & 0.085 & 0.051 & 0.008 \\
2 & Brand1 & -0.114 & -0.145 & 0.414 & 0.619 & 0.409 & 0.398 \\
2 & Brand2 & -0.172 & -0.734 & 0.401 & 0.378 & 0.616 & -0.961 \\
2 & Brand3 & 0.053 & 0.843 & 0.388 & 0.342 & 1.133 & 0.394 \\
2 & Brand4 & 0.214 & 0.915 & 0.416 & 0.459 & 1.096 & -0.929 \\
3 & Brand1 & 0.018 & -0.441 & 0.394 & 0.292 & 0.377 & 1.161 \\
3 & Brand2 & -0.014 & -0.406 & 0.399 & 0.814 & 0.745 & -0.717 \\
3 & Brand3 & 0.011 & 0.817 & 0.393 & 0.263 & 0.383 & -0.352 \\
\hline
\end{tabular}


Table 5a: Prescription Model Results (Joint Model - Common Parameter Estimates)

\begin{tabular}{lcc}
\hline Parameter & Posterior Means Estimate & Posterior Probability $^{\text {a }}$ \\
\hline \multicolumn{2}{c}{ INTERACTION BETWEEN DRUG CHARACTERISTICS AND MANUFACTURERS } & MARKETING \\
ACTIONS TOWARDS PHYSICIANS & 0.381 & 1.00 \\
\hline Effectiveness * Detailing & 0.154 & 0.83 \\
\hline Effectiveness * Meeting & 0.023 & 0.98 \\
\hline No. of Side Effects * Detailing & 0.031 & 0.81 \\
\hline No. of Side Effects * Meeting & CARRY-OVER EFFECTS & 1.00 \\
\hline \multicolumn{1}{c}{ INTERACTION BETWEEN DRUG CHARACTERISTICS AND PATIENT REQUESTS } \\
\hline Effectiveness * Patient Request & 0.131 & 0.99 \\
\hline No. of Side Effects * Patient Request & -0.029 & 1.00 \\
\hline & 2.476 & 1.00 \\
\hline ln_lag(Prescription) & 0.116 & 1.00 \\
\hline Effectiveness *ln_lag(Prescription) & -0.032 & 1.00 \\
\hline No. of Side Effects *ln_lag(Prescription) & MAIN EFFECTS & 1.00 \\
\hline
\end{tabular}

${ }^{a}$ The posterior probability is the probability that the parameter is less than or greater than zero. 
Table 5b: Prescription Model Results (Joint Model - Category 1, Brand Specific Parameter Estimates)

\begin{tabular}{lcc}
\hline Parameter & Posterior Means Estimate & Posterior Probability $^{\text {a }}$ \\
\hline Samples & 2.657 & \\
\hline Competitive Samples & -0.459 & 1.00 \\
\hline Competitive Prescription & 0.064 & 0.89 \\
\hline & BRAND 2 & 1.00 \\
\hline Samples & 0.002 & 0.58 \\
\hline Competitive Samples & -0.015 & 1.00 \\
\hline Competitive Prescription & 0.056 & 0.98 \\
\hline & BRAND 3 & \\
\hline Samples & 0.325 & 0.92 \\
\hline Competitive Samples & -0.032 & 1.00 \\
\hline Competitive Prescription & 0.066 & 1.00 \\
\hline Samples & BRAND 4 & 0.48 \\
\hline Competitive Samples & 0.000 & 1.00 \\
\hline Competitive Prescription & -0.041 & 1.00 \\
\hline
\end{tabular}

${ }^{a}$ The posterior probability is the probability that the parameter is less than or greater than zero. 
Table 6a: Sample-Dispensing Model Results (Joint Model - Common Parameter Estimates)

\begin{tabular}{lcc}
\hline Parameter & Posterior Means Estimate & Posterior Probability \\
\hline \multicolumn{2}{l}{ INTERACTION BETWEEN DRUG CHARACTERISTICS AND MANUFACTURERS } \\
ACTIONS TOWARDS PHYSICIANS
\end{tabular}

${ }^{a}$ The posterior probability is the probability that the parameter is less than or greater than zero. 
Table 6b: Sample-Dispensing Model Results (Joint Model - Category 1, Brand Specific Parameter Estimates)

\begin{tabular}{llcc}
\hline & Parameter & Posterior Means Estimate & Posterior Probability $^{\mathbf{a}}$ \\
\hline Brand 1 & Competitive Samples & 2.657 & 1.00 \\
\hline Brand 2 & Competitive Samples & 0.009 & 0.79 \\
\hline Brand 3 & Competitive Samples & 0.325 & 0.91 \\
\hline Brand 4 & Competitive Samples & 0.000 & 0.61 \\
\hline
\end{tabular}

${ }^{a}$ The posterior probability is the probability that the parameter is less than or greater than zero. 
Table 7: Detailing to Effectiveness and to Side Effects Elasticities

\begin{tabular}{llcccc}
\hline Category & Brand & $\begin{array}{c}\text { Detailing to Effectiveness Elasticity } \\
\text { Prescription } \\
\text { Model }\end{array}$ & $\begin{array}{c}\text { Dample-Dispensing } \\
\text { Model }\end{array}$ & $\begin{array}{c}\text { Detailing to Side Effects Elasticity } \\
\text { Prescription } \\
\text { Model }\end{array}$ & $\begin{array}{c}\text { Sample-Dispensing } \\
\text { Model }\end{array}$ \\
\hline 1 & Brand1 & -0.648 & -1.667 & 0.796 & 1.186 \\
1 & Brand2 & 0.402 & -0.716 & 0.599 & 0.909 \\
1 & Brand3 & -0.275 & 0.773 & 1.082 & 0.560 \\
1 & Brand4 & -0.145 & -1.855 & 1.099 & 0.317 \\
2 & Brand1 & -1.710 & -1.415 & 0.491 & 1.095 \\
2 & Brand2 & -0.795 & -0.267 & 1.061 & 0.958 \\
2 & Brand3 & -0.543 & 0.023 & 0.896 & 1.114 \\
2 & Brand4 & -1.847 & -1.867 & 0.972 & 0.737 \\
3 & Brand1 & 0.423 & -1.814 & 0.236 & 1.173 \\
3 & Brand2 & -1.247 & -0.202 & 0.639 & 0.318 \\
3 & Brand3 & -0.539 & 0.924 & 1.184 & 0.535 \\
3 & Brand4 & -1.387 & -1.217 & 0.587 & 0.220 \\
\hline
\end{tabular}




\section{Publications in the Report Series Research ${ }^{*}$ in Management}

\section{ERIM Research Program: "Marketing"}

2007

Marketing Communication Drivers of Adoption Timing of a New E-Service Among Existing Customers

Remco Prins and Peter C. Verhoef

ERS-2007-018-MKT

http://hdl.handle.net/1765/9405

Indirect Network Effects in New Product Growth

Stefan Stremersch, Gerard J. Tellis, Philip Hans Franses and Jeroen L.G. Binken

ERS-2007-019-MKT

http://hdl.handle.net/1765/9406

Demand-Driven Scheduling of Movies in a Multiplex

Jehoshua Eliashberg, Quintus Hegie, Jason Ho, Dennis Huisman, Steven J. Miller, Sanjeev Swami, Charles B. Weinberg and Berend Wierenga

ERS-2007-033-MKT

http://hdl.handle.net/1765/10069

Identifying Unknown Response Styles: A Latent-Class Bilinear Multinomial Logit Model

Joost van Rosmalen, Hester van Herk and Patrick J.F. Groenen

ERS-2007-045-MKT

http://hdl.handle.net/1765/10463

The Debate on Influencing Doctors' Decisions: Are Drug Characteristics the Missing Link?

Sriram Venkataraman and Stefan Stremersch

ERS-2007-056-MKT

A complete overview of the ERIM Report Series Research in Management:

https://ep.eur.nl/handle/1765/1

ERIM Research Programs:

LIS Business Processes, Logistics and Information Systems

ORG Organizing for Performance

MKT Marketing

F\&A Finance and Accounting

STR Strategy and Entrepreneurship 